\title{
Super-responders to bidirectional neoadjuvant chemotherapy showed prolonged survival
}

\author{
Paul H. Sugarbaker ${ }^{1}$, Kurt Van der Speeten ${ }^{2}$ \\ ${ }^{1}$ MedStar Washington Hospital Center, Washington, DC, USA; ${ }^{2}$ Department of Surgery, Hospital Oost-Limburg, Genk, Belgium \\ Correspondence to: Paul H. Sugarbaker, MD. MedStar Washington Hospital Center, Washington, DC, USA. Email: Paul.Sugarbaker@outlook.com; \\ Kurt Van der Speeten. Department of Surgery, Hospital Oost-Limburg, Genk, Belgium. Email: Kurt.Vanderspeeten@zol.be. \\ Comment on: Canbay E, Canbay Torun B, et al. Surgery with hyperthermic intraperitoneal chemotherapy after response to induction chemotherapy \\ in patients with peritoneal metastasis of gastric cancer. J Gastrointest Oncol 2021;12:S47-56.
}

Submitted Dec 16, 2020. Accepted for publication Mar 16, 2021.

doi: 10.21037/jgo-2020-11

View this article at: http://dx.doi.org/10.21037/jgo-2020-11

Canbay and colleagues from Istanbul present as a rationale for their treatment of gastric cancer plus PM, "The best outcomes in cancer treatment occur with complete resection". Their manuscript is not a review (1). It presents primary data from a single institution treatment protocol. Preoperatively, gastric cancer patients with peritoneal metastases have a laparoscopic HIPEC and bidirectional intraperitoneal and systemic chemotherapy using combinations of cisplatin, docetaxel and fluorouracil, mirroring the Japanese protocol used by Yonemura et al. There was a modest decrease in PCI (an assessment of visible cancer nodules) and a marked reduction of ascites and positive cytology (an assessment of single cancer cells). Patients who had clinical evidence of response had a repeat laparoscopy; a reduced PCI and absence of ascites in a good performance patient caused the patient to be recommended for radical gastrectomy with an attempt at complete cytoreduction plus HIPEC with cisplatin, docetaxel and ifosfamide. The intraperitoneal port was left in place for an additional 3 cycles of the bidirectional intraperitoneal and systemic chemotherapy. As one first evaluates this multistep treatment plan, the toxicities expected may seem prohibitive. However, the repeated treatments by HIPEC and by intraperitoneal and systemic infusion are with moderate to low doses of chemotherapy. Patient tolerance to the repeated moderate doses of chemotherapy is a unique feature of this treatment plan. As such; this combined, consecutive and cycled regimen of surgery with both systemic and locoregional multidrug chemotherapy regimens seeks to maximize locoregional and systemic control while minimizing toxicity. Preliminary data are encouraging with 34 of the 53 protocol patients going to surgery. There were 22 patients who had conversion surgery documented by a CC- $0 / 1$ resection. This was the goal of the aggressive treatment plans. Median survival of 22 patients having complete resection was 32 months as compared to 19 months for 53 protocol patients. Low PCI was an important determinate of benefit. Eighteen percent of patient survived 5 years. As such this tail of the survival curve should be considered level 1C evidence in favor of the concept. More data from this group is expected in the future. The concept of repeated low doses of chemotherapy administered by intraperitoneal and systemic routes with and without heat as a preparation for conversion surgery demands our attention.

For all the NIPEC efforts, a major obstacle is a technical one and relates to the long-term function of an IP port. We asked Emel Canbay to tell us her secrets. She responded as follows: (I) The cycles of IP chemotherapy are limited to 3 prior to surgery and 3 after. More than 3 cycles just results in port-related problems. (II) The IP port is replaced at the time of surgery. (III) A DistricAth IP plastic port with silicone tubing is used (Districlass medical SA, Saint-Etienne, France). (IV) Ports are flushed with heparinized saline before and after each chemotherapy instillation.

\section{Acknowledgments}

Funding: None. 


\section{Footnote}

Provenance and Peer Review: This article was commissioned by the editorial office, Fournal of Gastrointestinal Oncology for the focused issue "Intraperitoneal Chemotherapy for Peritoneal Metastases: HIPEC, EPIC, NIPEC, PIPAC and More". The article did not undergo external peer review.

Conflicts of Interest: Both authors have completed the ICMJE uniform disclosure form (available at http:// dx.doi.org/10.21037/jgo-2020-11). The focused issue was sponsored by the Peritoneal Surface Oncology Group International (PSOGI). Drs. PHS and KVDS served as the unpaid Guest Editors of the focused issue. The authors have no other conflicts of interest to declare.

Ethical Statement: The authors are accountable for all aspects of the work in ensuring that questions related to the accuracy or integrity of any part of the work are appropriately investigated and resolved.

Open Access Statement: This is an Open Access article distributed in accordance with the Creative Commons Attribution-NonCommercial-NoDerivs 4.0 International License (CC BY-NC-ND 4.0), which permits the noncommercial replication and distribution of the article with the strict proviso that no changes or edits are made and the original work is properly cited (including links to both the formal publication through the relevant DOI and the license). See: https://creativecommons.org/licenses/by-nc-nd/4.0/.

\section{References}

1. Canbay E, Canbay Torun B, et al. Surgery with hyperthermic intraperitoneal chemotherapy after response to induction chemotherapy in patients with peritoneal metastasis of gastric cancer. J Gastrointest Oncol 2021;12:S47-56.
Cite this article as: Sugarbaker PH, Van der Speeten K. Super-responders to bidirectional neoadjuvant chemotherapy showed prolonged survival. J Gastrointest Oncol 2021;12 (Suppl 1):S57-S58. doi: 10.21037/jgo-2020-11 